\title{
THE TOPOGRAPHY AND SURFACE CHARACTERISTICS OF THE LARSEN ICE SHELF, ANTARCTICA, USING SATELLITE ALTIMETRY
}

\author{
By JefF Ridley, Wyn Cudlip, NeIl Mcintyre, and Chris Rapley \\ (Mullard Space Science Laboratory, University College London, Holmbury St. Mary, \\ Dorking, Surrey RH5 6NT, England)
}

\begin{abstract}
A comprehensive survey of the Larsen Ice Shelf has been conducted using precise orbit and retracked Seasat radar-altimeter data with editing of erroneous values resulting from intrumental artefacts. Contour maps of elevation and radar back-scatter (with absolute accuracies of $1 \mathrm{~m}$ and $2 \mathrm{~dB}$, respectively) have been produced and it has also been possible to map rifts, grounding points, rough terrain, and about $30 \%$ of the ice shelf's seaward margin. Ice thicknesses derived from these elevation data show broad agreement with those derived from previous airborne radio-echo surveys. The maps of parameters measured by Seasat represent a very substantial improvement over those previously available. They thus provide a reference against which comparison may be made with a view to detecting substantial climatic changes. This is of particular interest since, as the most northerly major ice shelf in Antarctica, the Larsen Ice Shelf may be more sensitive than others to global climatic trends.
\end{abstract}

\section{INTRODUCTION}

The role of ice shelves in the dynamics of ice sheets has been discussed widely in recent years. There is broad agreement that they form important elements in interactions of the Antarctic ice sheet with both the oceans and the atmosphere (Hughes, 1973; Robin, 1979), but evidence is not yet available to establish how sensitively they respond to changing oceanic and atmospheric conditions. The Larsen Ice Shelf lies further north than any other major Antarctic ice shelf and, in its less extreme polar environment, it may be particularly sensitive to climate change. It thus represents an important candidate for the detection of the effects of global warming due to the greenhouse effect.

The Larsen Ice Shelf lies to the eastern side of the Antarctic Peninsula, extending for more than $500 \mathrm{~km}$ between James Ross Island (lat. $64^{\circ} 30^{\prime} \mathrm{S}$., long. $59^{\circ} 00^{\prime} \mathrm{W}$.) and Hearst Island (lat. $69^{\circ} 15^{\prime} \mathrm{S}$., long. $62^{\circ} 15^{\prime} \mathrm{W}$.) on the Wilkins Coast. Geographically, it is divided into three major parts by Jason and Kenyon Peninsulas, the former protruding about $100 \mathrm{~km}$ from the mainland. The eastern margin of the ice shelf is disturbed in a number of places by localized areas of grounding, such as Gipps Ice Rise and Robertson Island. Structurally, it is highly variable and owes its origin both to a large number of tributary glaciers flowing from the Antarctic Peninsula and to the freezing of sea-water. Rifts, stagnant ice (Fleet, 1965), undulations (Kennett, 1965), and glacier tongues (Reece, 1950) have been identified during traverses of its surface, and the ice shelf's overall character is irregular and broken.

The earliest attempts to measure the ice shelf's surface elevations were based on measurements of barometric pressure or gravity anomaly (Mason, 1950; Fleet, 1965; Kennett, 1965, 1966). These were limited in their spatial extent and did not provide sufficient accuracy for geophysical investigations. Two seasons of airborne radio echo-sounding (Renner, 1969; Ewen Smith, 1972) provided a much quicker and more accurate means of deriving surface elevation (from ice-thickness measurements), but the coverage obtained was limited to specific transects along the flight lines. No elevation data have been recorded since then, and other surveying of the ice shelf has been limited to aerial photography (Ronne Antarctic Research Expedition, 1946-47) and satellite imagery. The latter has come from TIROS AVHRR and Landsat MSS, but has been plagued by severe cloud cover. No single high-resolution survey of the ice shelf's areal extent has been possible, although periodic sampling has shown that significant changes to the coastline have occurred due to the calving of a number of major icebergs (Swithinbank and others, 1977; Jacobs and Barnett, 1987).

Satellite microwave sensors offer the best means of surveying the Larsen Ice Shelf on a regular basis, since they are unaffected by cloud and have a day and night capability. Satellite synthetic aperture radar, with its ability to produce high-resolution (tens of metres) imagery, has the greatest potential, but this is currently limited in the Antarctic by the absence of suitable instruments and telemetry receiving stations (however, the launch of ERS-1 in 1990 and the planned provision of receiving stations by the West Germans and the Japanese may overcome this).

In the meantime, satellite radar altimeters, although not imaging instruments, can be used to carry out topographic and back-scattter mapping. The potential of oceanographic satellite altimeters to provide elevation measurements of high accuracy over ice masses was demonstrated with data from Geos-3 (Brooks and others, 1978) and Seasat (Zwally and others, 1983). Brooks and others (1983) were the first to use satellite-altimeter data to map an ice shelf (Amery Ice Shelf). Subsequently, Zwally and others (1987) produced elevation maps of the Amery and Fimbul Ice Shelves and also used the technique of Thomas and others (1983) to locate the associated ice fronts to an accuracy of between 100 and $1000 \mathrm{~m}$. The application of altimetry to ice-shelf surveying was further extended by Partington and others (1987) in their detection of grounding lines and crevassed zones.

The objective of this paper is to present results from a new survey of the Larsen Ice Shelf using Seasat radar altimetry. This study has permitted, for the first time, contouring of surface elevations over the entire ice shelf, and the mapping of its margins, surface topography, and radar back-scatter characteristics. The data, collected for the most part during July and August 1978, provide the first comprehensive data set for the Larsen Ice Shelf against which future surveys may be compared.

\section{SEASAT DATA ANALYSIS}

\section{Introduction}

The Seasat satellite, launched on 28 June 1978, failed unexpectedly on 10 October. Despite the brevity of the mission, the volume of altimeter data is relatively large, 
particularly when dealing with the telemetered echo wave forms which are required for the study of non-ocean surfaces.

For this analysis, data from one cycle of Seasat's $17 \mathrm{~d}$ repeat orbit were selected, giving regular coverage of the ice shelf with a cross-track spacing of about $40 \mathrm{~km}$. Other orbits which enhanced the spatial coverage of the ice shelf were also used, providing 44 tracks in all. During the final month of the Seasat mission, the satellite was in a $3 \mathrm{~d}$ repeat orbit which resulted in a cross-track spacing of about $230 \mathrm{~km}$. Due to this wide cross-track spacing, only two tracks passed over the central part of the ice shelf. For each of these, several repeat orbits were processed in order to check the repeatability of the observations. Figure 1 shows the spatial distribution of the ground tracks superimposed on the coastline (British Antarctic Survey, 1979; Directorate of Overseas Surveys, 1981). Gaps in the tracks represent areas over which the radar altimeter was unable to maintain lock on the surface. Loss of lock occurred mainly immediately inland of the ice edge due to the sudden elevation change at the ice cliff. It also occurred at the transition from ice shelf to rougher inland ice.

\section{Deriving surface elevation}

Retracking

The Seasat altimeter attempted to maintain the leading edge of the return echoes at the centre of its range window (the tracking point). Each echo was digitized using 60 bins, each with an effective range width of $0.47 \mathrm{~m}$ (for a full description of the Seasat altimeter see MacArthur (1978)). Since the tracker was designed to operate over the ocean, problems arose over non-ocean surfaces due to rapid variations in elevation and/or surface back-scatter intensity.

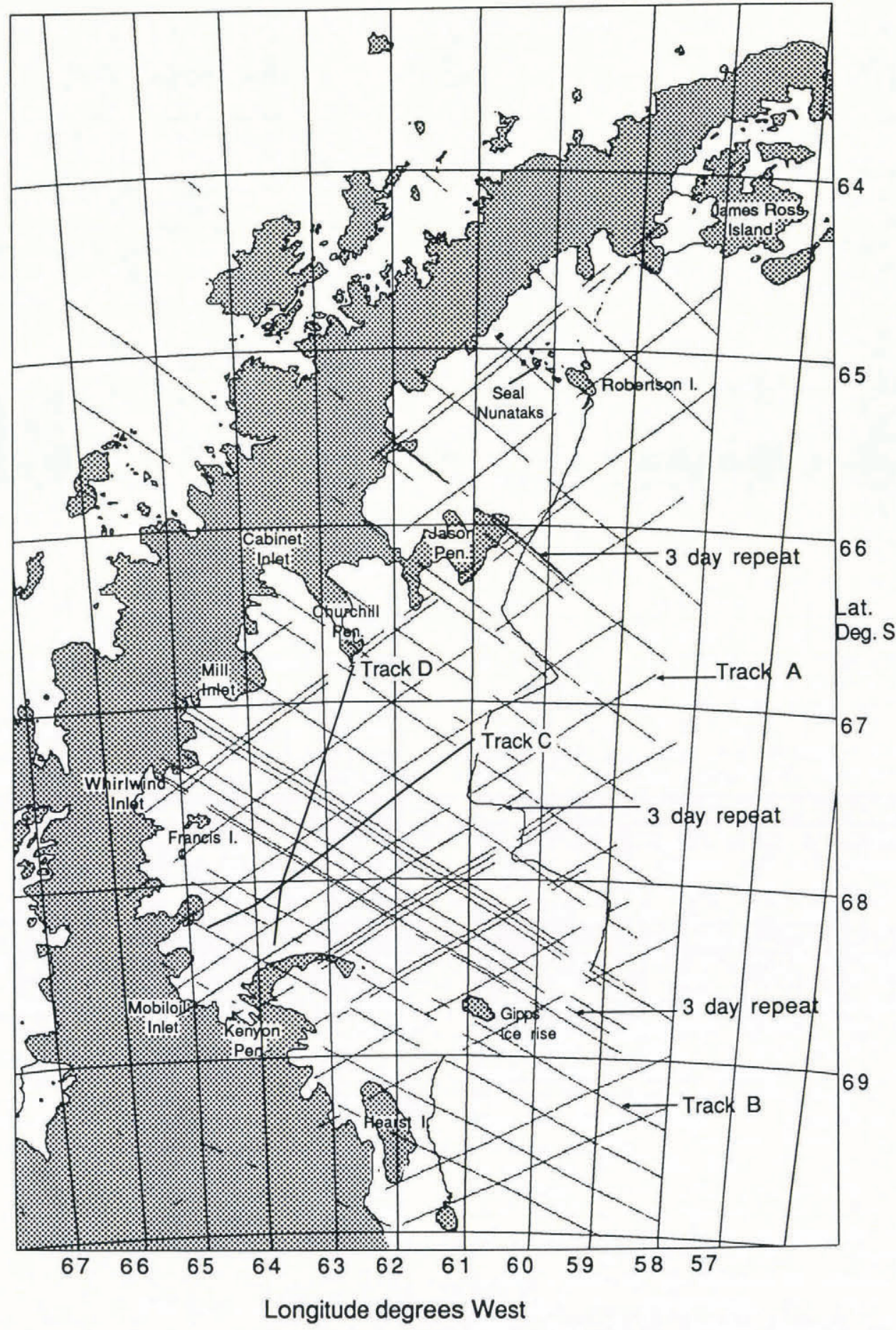

Fig. 1. Seasat ground tracks used in this paper. Tracks $A$ and $B$ relate to the elevation profiles shown in Figure 5; tracks $C$ and $D$ show the locations of the ice-thickness profiles given in Figure 7. The coastline shown is derived from British Antarctic Survey (1979) and Directorate of Overseas Surveys (1981). 
In particular, the tracker was of ten unable to maintain the leading edge of the return at the tracking point; in order to estimate the true range to the surface, the offset of the leading edge from the middle of the range window has to be measured during the data analysis on a process called retracking (Martin and others, 1983).

Ideally, retracking would determine the offset between the tracking point and the position on the leading edge of the wave form corresponding to the mean surface height. In practice, however, this latter position is not known a priori. For a flat surface with a Gaussian distribution of scatterers, the mean surface height corrresponds to the half-power point of the leading edge. However, for a surface such as an ice shelf, the distribution of surface heights will not, in general, be Gaussian. Furthermore, the half-power point cannot be exactly determined due to signal noise. Martin and others (1983) estimated the peak power and mid-point of the leading edge for wave forms over the Greenland ice sheet by fitting them with a five or nine parameter smooth function. This technique, however, assumes a Gaussian distribution of surface heights and a homogeneous surface (i.e. no distortion of wave forms due to the presence of, for example, crevasses in the altimeter footprint), and so is limited to nearly "ocean-like" wave forms (with the additional possibility of a double-ramped leading edge).

We chose to retrack using a theshold retracking technique which simply determines the first location on the leading edge (using a linear interpolation between the discrete bin values) of the $50 \%$ power point. We take the power to be represented by the "amplitude" of the wave form as described below. The advantage of this technique is that it makes no a priori assumptions about the nature of the observed surface and is very robust, i.e. gives consistent results for noisy non-ocean-like wave forms. The disadvantage of this technique is that it can introduce bias into the measurement of surface height, although, as described below, for a wave form with a simple shape, estimates of this bias can be made, and, for complex wave forms, the effect of the bias is negligible in the light of the additional uncertainties in interpreting the measurements.

Before retracking, we characterize the shape of the wave form using two parameters, amplitude and width, in a manner first described by Wingham and others (1986). The amplitude is defined as twice height of the vertical centre of gravity of the wave form. The "width" is the width of a box whose height equals the wave-form amplitude and whose area equals the area of the wave form. The width can be used as a quantitative indicator of wave-form shape; a width of a few bins indicates a very smooth surface giving rise to a narrow quasi-specular wave form, whilst a width of 30 bins (half the range window width) is typical for ocean-like wave forms from a more diffusely scattering surface.

As a further development, we calculate these parameters from the square of the bin sample values, as follows:

$$
\begin{aligned}
\text { Amplitude } & =\left[2 \sum_{i=1}^{i=60}\left(0.5 r^{2}(i) r^{2}(i) / \sum_{i=1} r^{2}(i)\right]^{\frac{1}{2}}\right. \\
\text { Width } & =\left[\sum_{i=1}^{i=60} r^{2}(i)\right]^{2} / \sum_{i=1}^{i=60} r^{4}(i)
\end{aligned}
$$

where $r(i)$ is the sample in each of the 60 range bin samples. This reduces the retracking bias for wave forms with extended leading-edge slopes (i.e. surfaces with significant large-scale roughness).

In order to assess the dependency of this method of retracking on surface roughness, wave-form shape, and signal noise, simulated wave forms were modelled from a surface with a Guassian height distribution of scatterers for which the exact location of the mean surface and peak return power were known. The simulated wave forms were retracked using the above technique and the results compared with the "true" values. a

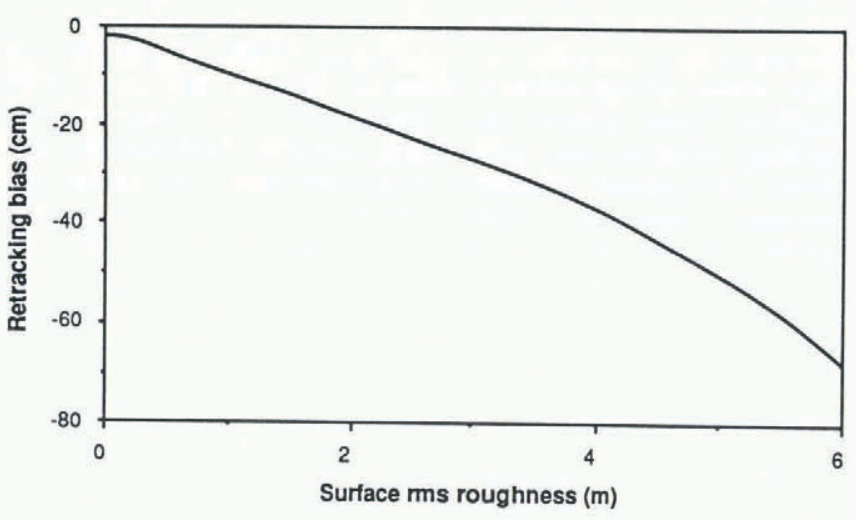

b

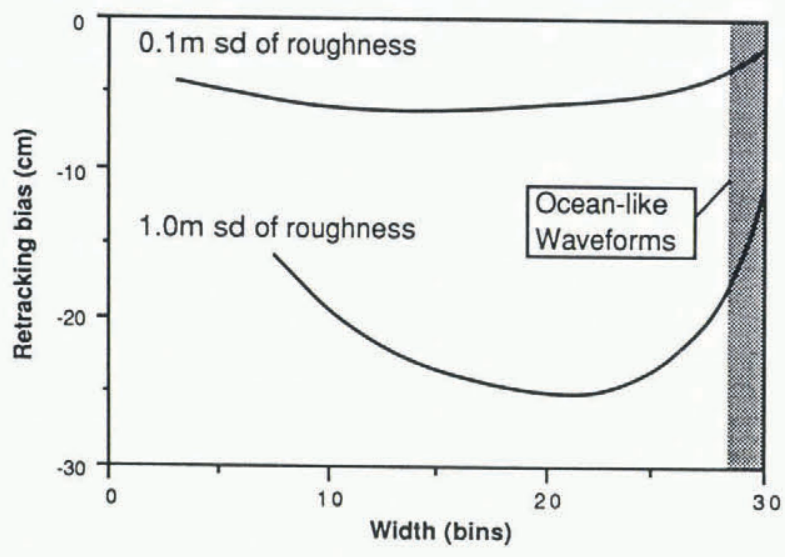

Fig. 2.a. Retracking bias as a function of surface roughness for ocean-like wave forms. $b$. Retracking bias as a function of wave-form width.

Figure 2a shows the bias resulting from the effect of surface roughness on noiseless ocean-like wave forms (width $=29$ bins). The effect of surface roughness is essentially linear with about $-0.13 \mathrm{~m}$ range bias for $1 \mathrm{~m}$ r.m.s. surface roughness (equivalent to $4 \mathrm{~m}$ significant wave height over the ocean). The effect of surface roughness also depends on wave-form shape, as shown in Figure $2 b$, and it can be seen that, for example, for a surface roughness of $1 \mathrm{~m}$ r.m.s. the bias increases to a maximum of $-0.25 \mathrm{~m}$ for wave forms with a width of about 21 bins. If noise is superimposed on the modelled wave forms, then the bias is reduced because the effect of squaring the bin values emphasizes the wave-form samples containing higher power. Repeatedly simulating wave forms with superimposed noise from an ocean-like surface with $1 \mathrm{~m}$ r.m.s. roughness produced a retrack bias of $-0.060 \pm 0.017 \mathrm{~m}$ compared with the $-0.13 \mathrm{~m}$ for the noiseless case. Over the bulk of the Larsen Ice Shelf, the wave forms are ocean-like with an r.m.s. roughness of about $1 \mathrm{~m}$. In the area mapped the roughness never exceeds $2 \mathrm{~m}$ r.m.s. The surface-elevation bias over the Larsen Ice Shelf due to surface roughness will, therefore, rarely exceed $0.10-0.15 \mathrm{~m}$.

In addition to surface roughness, which affects the leading edge of the wave form, the width of the wave form is affected by a non-horizontal trailing edge to the wave form (i.e. non-ocean-like wave form). The slope of the trailing edge is governed by three factors: (i) peculiar surface geometries (e.g. crevasses or small bright targets in the footprint), (ii) the polar response of the surface scattering, and (iii) the surface slope (or antenna offpointing) which can distort the wave form through its interaction with the antenna polar response. Without information about the surface geometry, little can be done in case (i) except to note that surface-elevation estimates will be reduced in accuracy. For case (ii), the effect has 
been modelled as explained above and Figure $2 b$ shows the dependence of retrack bias on wave-form width. In case (iii), the wave-form shape will become distorted when the surface slope (or antenna mispointing angle) approaches the half-width of the antenna beam of $0.8^{\circ}$. In particular, with surface slopes greater than about $0.2^{\circ}$, the slope of the trailing edge of the wave form becomes positive, i.e. the wave-form power continues to increase after the top of the leading edge. In these circumstances, estimating the mid-point of the leading edge becomes more difficult. Fortunately, apart from the landward periphery of the ice shelf which is not included in our analysis, the surface slopes are significantly less than $0.2^{\circ}$ (generally in the range $0.01-0.05^{\circ}$ ), and so retracking bias from this cause can be ignored.

In order to assess the effect of signal noise on the estimate of the location of the half-amplitude threshold, repeat passes from each of the $3 \mathrm{~d}$ repeat tracks were analysed. Over the central areas of the ice shelf, the r.m.s. variation in difference between repeat tracks (which were laterally offset by less than a kilometre) had values of between 0.2 and $0.25 \mathrm{~m}$, and these reduced to about $0.1 \mathrm{~m}$ if the data were first averaged to a $1 \mathrm{~Hz}$ sampling rate. In general, then, the precision of the ice-shelf range measurements is similar to that achieved over the ocean (Townsend, 1980).

\section{Mean wave-form analysis}

In addition to the problem of estimating the location of the mid-point of the leading edge of the wave form, there is also the problem of determining the relationship between that point and the true mean surface. The height distribution of scatterers forming the surface under observation affects both the shape of the leading edge and the position on the leading edge corresponding to the mean surface. In order to assess this relationship, an analysis of the exact shape of the leading edge is required and so, to this end, several average wave forms were generated by averaging about $20010 \mathrm{~Hz}$ wave forms in order to reduce the effect of the noise. When averaging over the ice shelf, care was taken to ensure that wave forms did not include obviously anomalous features such as those due to rifts, which are described later.

Figure 3 shows two average wave forms. The first was generated from wave forms over a stretch of ocean in the South Atlantic which had a similar leading-edge slope (a significant wave height of about $4 \mathrm{~m}$ ) to those used to construct the second from the flat central part of the ice shelf. The derivative of the leading edge of a wave form represents the height probability density function (PDF) of surface scatterers within the pulse limited footprint (assuming no correlation of effective back-scatter with height). The first half of the derivatives has been subtracted from the second half to reveal any asymmetry in the height PDF. The ocean wave-form derivative has a Gaussian form
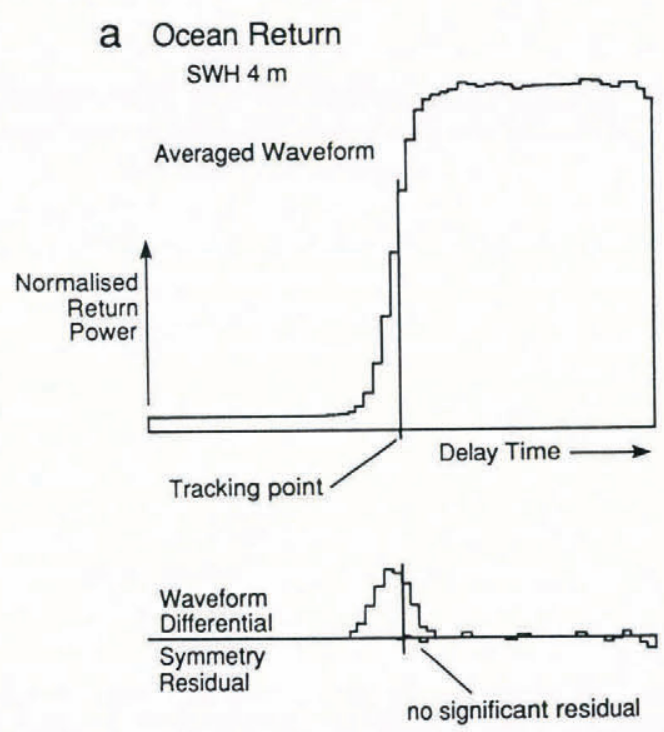

and no noticeable asymmetry, as is expected for an ocean surface, with waves of this magnitude. The mean ice-shelf wave form appears similar but the derivative shows some asymmetry. The form of the asymmetry suggests that the distribution of scatterers is non-Gaussian with more above the mean surface, and this is consistent with the idea that the surface may have superimposed linear features such as fields of sastrugi. If the observed asymmetry had been in the opposite direction, then it would have been suggestive of structure beneath the mean surface, such as crevassing or volume scattering due to surface penetration (Ridley and Partington, 1988).

If we assume that the position on the leading edge of the wave form corresponding to the mean surface is represented by the peak of the derivative curve, then we can estimate the retracking bias introduced by using half the amplitude as the retracking point (see above). In this way, the bias for the mean ice-shelf wave form is found to be about $0.2 \mathrm{~m}$. Since this is less than the other absolute errors associated with the uncertainty in the satellite orbit and the state of the tides, it is not considered further.

\section{Other corrections}

In order to derive surface elevation, which is measured with respect to the geoid (mean sea-level), from the wave-form range estimate, several additional parameters have to be determined. The surface elevation relative to the geoid $(E g)$ is given by:

$$
E g=(H e-G e)-(R+C)
$$

where $\mathrm{He}$ is the satellite height and $\mathrm{Ge}$ the geoid height both relative to the Seasat Reference Ellipsoid ( $a=$ $6378.137 \mathrm{~km}, f=1 / 298.257) . \quad R$ is the retracked range estimate and $C$ represents all the corrections which have to be applied to the range value and includes instrumental calibrations, the spacecraft centre of gravity offset, and atmospheric corrections. For ice-shelf elevations, a correction for the state of the tide also has to be included and, although the Seasat Geophysical Data Record (GDR) tidal corrections may be in considerable error, the effect of this is minimized through the least-squares adjustment of the orbits at their cross-overs as discussed later. Both the satellite heights and geoid values are imprecisely known and are the main contributors to the final inaccuracy of the results. The satellite height supplied with the wave-form data is estimated to have an accuracy of only $\sim 5 \mathrm{~m}$, although higher-accuracy orbit data are available (see later). The best estimates available to us for the geoid were from the GEMIOB geoid model provided on the Seasat GDR tapes. The accuracy of this geoid model is about $1-2 \mathrm{~m}$ in the north-west Atlantic, although errors of several metres with wavelengths of the order of several hundred kilometres have been noted elsewhere (Marsh and Martin, 1982).

The uncertainty in the surface elevation due to errors

\section{b Ice Shelf Return} SWH $4 \mathrm{~m}$
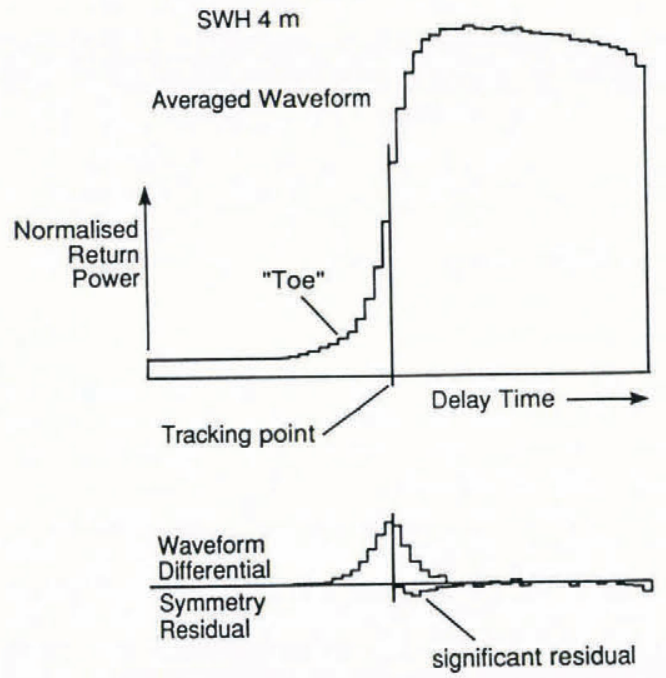

Fig. 3. Averaged wave forms and their first derivatives from (a) the South Atlantic Ocean and (b) the Larsen Ice Shelf. 
in the satellite height and the corrections mentioned above, can be minimized through an analysis of elevation differences at orbit cross-overs. It is normal to apply a bias and tilt to each orbit so as to minimize the r.m.s. of the cross-over differences but, in this case, because of the short track lengths, only orbit bias was applied. The result was an improvement in the r.m.s. of the cross-over residuals from an initial $3 \mathrm{~m}$ to $0.5 \mathrm{~m}$. This technique results in an unknown overall elevation offset, and so the surface was adjusted to match the elevations derived from a single well-defined orbit (number 655, 11.8 .78 at 20.15 GMT) from the $17 \mathrm{~d}$ repeat cycle for which the Seasat $0.5 \mathrm{~m}$ r.m.s. orbit (Marsh and others, in press) was available. For this reference orbit, the required corrections (for atmosphere and tide) were taken from the corresponding GDR data. However, since the Schweiderski model for tidal corrections in the Weddell Sea is thought to be poor, this tidal correction may be in error.

The main factors affecting the final accuracy of the derived surface elevations are, therefore, those arising from the cross-over analysis $(0.5 \mathrm{~m})$, the reference-orbit error $(0.5 \mathrm{~m})$, the atmospheric corrections for the reference orbit $(0.4 \mathrm{~m})$, the retracking error $(0.1 \mathrm{~m})$, and the errors in the GEM10B geoid model. These errors are quadratically summed, $0.82 \mathrm{~m}$, and to this is added the $0.2 \mathrm{~m}$ bias from non-Gaussian wave forms and $0.06 \mathrm{~m}$ bias from the technique for measurement of wave-form amplitude with $1 \mathrm{~m}$ r.m.s. roughness. Excluding the tidal error in the reference orbit and the geoid error, which will be discussed below, we estimate absolute accuracy of the surface elevations to be $\pm 1.08 \mathrm{~m}$ with respect to the Seasat reference ellipsoid.

\section{Ice-margin mapping}

Thomas and others (1983) have demonstrated that short sections of ice-sheet edges can be mapped using the characteristics of the Seasat altimeter range measurements just before the altimeter loses lock. This is possible because, on transit of an abrupt change in elevation, the altimeter continues to measure the slant range to the original surface in a process known as "off-ranging". This technique has been applied by Zwally and others (1987) to map the edge of the Amery Ice Shelf, and we have used a similar technique to map the Larsen Ice Shelf edge. The method is most successful on a transition from brightly reflecting sea ice to more diffuse ice shelf as was the case for most of the Larsen Ice Shelf front. From lat. $59^{\circ}$ to $65.2^{\circ} \mathrm{S}$., however, the ice shelf was flanked by a stretch of sea ice with a similar intensity of back-scatter. At these intersections, only the location of the crossing point could be determined, rather than a short section of the ice front. In a few cases, when the ice cliff was not more than $20 \mathrm{~m}$ high, the altimeter maintained lock across the transition. In other cases, when the ground track traversed an ice rise at the edge of the ice shelf, lock was lost due to the very chaotic ice-shelf surface and its low return power.

In all, 41 intersections of the ice front were obtained, resulting in segments of between 1 and $18 \mathrm{~km}$ defining about $30 \%$ of the ice front. The results of this margin mapping are shown as a heavy dashed line on each of the later maps (Figs 5, 7, and 9).

\section{Contouring of surface elevations}

To create the surface-elevation contour map (Fig. 5), the fully corrected data were first binned into cells of $0.1^{3}$ latitude and longitude and then a uniform grid was produced using a linear interpolation of a triangulation. For clarity, the contour interval is limited to $2 \mathrm{~m}$, and those contours around the periphery of the ice shelf which were thought to be in error, due to the confusion in the radar return arising from the proximity of higher grounded ice, have been removed (see below).

\section{Grounding-line mapping}

The landward edge of an ice shelf is marked by the grounding line which is where an increase in surface gradient typically indicates that the ice is no longer floating. Using data from the Amery Ice Shelf, Partington and others (1987) showed that the location of the grounding zone could be identified by locating the start of the characteristic recession of the ice shelf's radar return out of the altimeter's range window. For much of the Larsen Ice Shelf, the surface is very rough and chaotic in the vicinity of the grounding line and it was found to be impossible to detect a clear change in surface gradient. Nevertheless, an estimate of the location of the grounding line, to an accuracy of the order $\pm 500 \mathrm{~m}$, could be made for 16 ground tracks. The positions are shown in Figure 7

\section{Radar back-scatter}

The normal-incidence radar back-scatter coefficient (sigma zero) was derived from the amplitude (Equation (2)) of the individual wave forms. The wave-form amplitude was converted to units of decibels by taking account of the altimeter's Automatic Gain Control and an offset derived from a comparison of wave-form amplitude with sigma zero values given in the Seasat GDRs for a section of track over the South Atlantic. This comparison could not be carried out over the ice shelf because GDRs are only valid for the oceans. The back-scatter map (Fig. 9), with a contour interval of $0.5 \mathrm{~dB}$, was constructed in the same way as the elevation map. The accuracy of fully calibrated backscatter measurements over the oceans has been estimated to be $\pm 1 \mathrm{~dB}$ (Townsend, 1980). We estimate the absolute accuracy on the back-scatter values over the Larsen Ice Shelf to be $\pm 2.0 \mathrm{~dB}$ since not all possible sources of error have been taken into account (e.g. satellite off-pointing and atmospheric losses).

\section{Surface features}

Surface roughness

An estimate of the amplitude of the surface roughness can be derived from the leading-edge width of the wave form in a manner similar to deriving the Significant Wave Height over the ocean. Partington and others (1987) demonstrated that the altimeter can also detect crevassed zones which are revealed when a "toe" extends from the base of the leading edge of the wave form. Our numerical modelling of wave forms (based on the work of Brown (1977) but with non-Gaussian surface-height distributions) which would arise from typical areas of crevassing or sastrugi fields results in wave forms similar to those observed with the altimeter. By visually identifying wave forms within the data set which consistently exhibit a characteristic "toe" prior to the leading edge, areas of relatively severe, but non-Gaussian, surface roughness have been outlined (Fig. 7).

\section{Rift detection and mapping}

Rifts, up to $100 \mathrm{~km}$ long, several kilometres wide, and tens of metres deep, in the Larsen Ice Shelf surface have been noted by previous surveys (Fleet, 1965). They can be identified in the altimeter data by the passage of a characteristic feature through a sequence of wave forms. This feature takes the form of a depression in part of the return wave form caused by the relative delay in the signal from the lower parts of the rift. By observing the parabolic path taken by such a feature as it migrates from the rear of the wave form to the leading edge and then back again, the position of the rift along the ground track and its approximate orientation can be determined. When the rifts become less than $500 \mathrm{~m}$ wide, these lower-power bins become lost in the random noise and cannot be identified unambiguously as continuous features. The ability to relocate such features in future missions may allow the transverse rate of motion of the ice to be measured.

An example of the movement of a rift feature through a sequence of Seasat wave forms is shown in Figure 4 together with the results of computer modelling of return wave forms on simulated terrain containing a vertical rift. The model divides the geometric structure of the surface into facets $100 \mathrm{~m}$ square and sums the power returned from each facet based on its assumed scattering properties. In this case, the sequence shown is the first half of that observed as the rift first enters the altimeter footprint. The subsequent parabolic recession of the feature to the rear of the wave form is a mirror repeat of that shown. The sequence is modelled with a rift consisting of an instantaneous drop in elevation of $10 \mathrm{~m}$ and a width of $700 \mathrm{~m}$.

In areas where the Seasat ground-track spacing is relatively dense, individual rifts can be traced across the ice 
a Seasat Waveforms

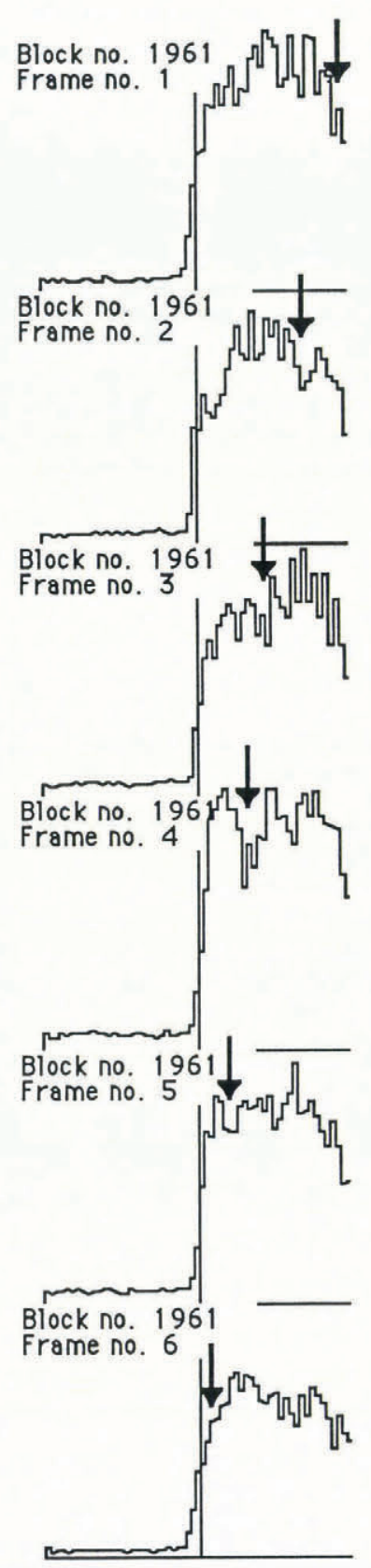

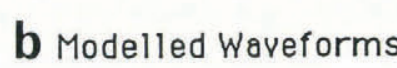

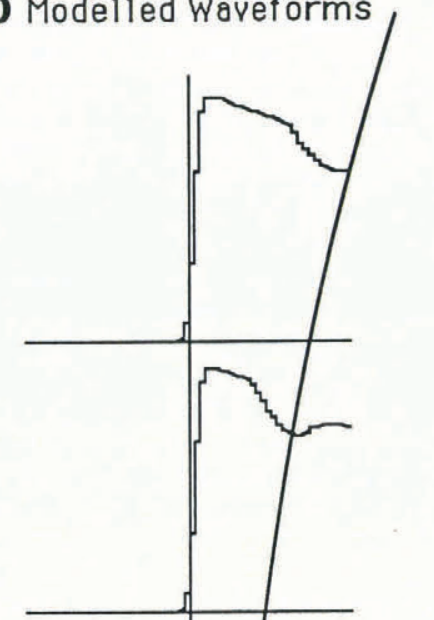

Modelled Surface

In Footprint
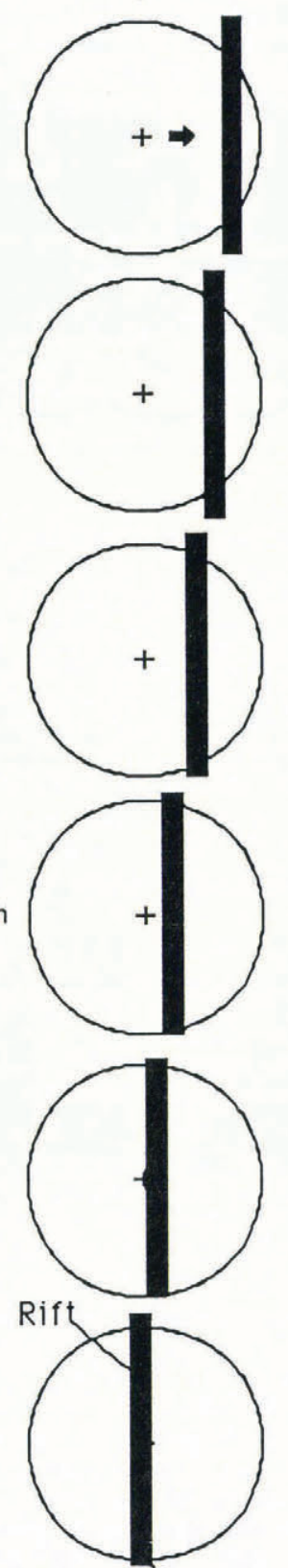

Fig. 4.a. A sequence of Seasat wave forms showing the migration of a feature of lower power return through the wave form, as would be expected during the overflight of a rift. b. Simulated wave forms modelling the same situation of a rift overflight and illustration of the altimeter's footprint and the parabolic passage of the depression in the wave form, due to the rift, through it.

shelf for many tens of kilometres. They tend to become narrower away from the ice shelf's seaward margin to the stage where the radar echo from the bottom is no longer discernible from the noise; from this point, the depth can no longer be determined, indicating that the cross-section has become V-shaped or that the floor has become very broken. Their presence, however, is still detectable, as they serve as an effective radar absorber resulting in a depression in the wave-form shape.

In areas of lower track density, the rifts have been interpolated across areas of no data if there appears to be an unambiguous association between rifts detected on adjacent tracks. Some rifts appear to be rather short and fade away over small distances.

\section{DISCUSSION}

\section{Elevations and surface features}

Figure 5 shows the surface-elevation contour map compiled according to the procedures described above. It is presented with a $2 \mathrm{~m}$ contour interval and covers areas believed to have data uncontaminated by factors such as off-nadir ranging to adjacent land. The gaps in contouring near the ice shelf's seaward margin, itself derived from the altimetry, are due to losses of lock caused by the step change in elevation. The distribution of large rifts and rough terrain is shown in Figure 7 along with that of crevassed areas. For the following description, the ice shelf has been considered in three distinct parts separated by Jason and Kenyon Peninsulas.

\section{Northern section}

The ice shelf north of Jason Peninsula is generally low-lying and does not exceed $38 \mathrm{~m}$ above sea-level (a.s.1.). The highest terrain is an elevated tongue of ice which forms an outflow from the area of Leppard Glacier. The relatively poor coverage caused by the wide spacing of the Seasat ground tracks may contribute to the anomalous feature where part of the glacier outflow appears to curve inland. The lowest elevations in this part of the ice shelf occur in the area of Robertson Island and the Seal 


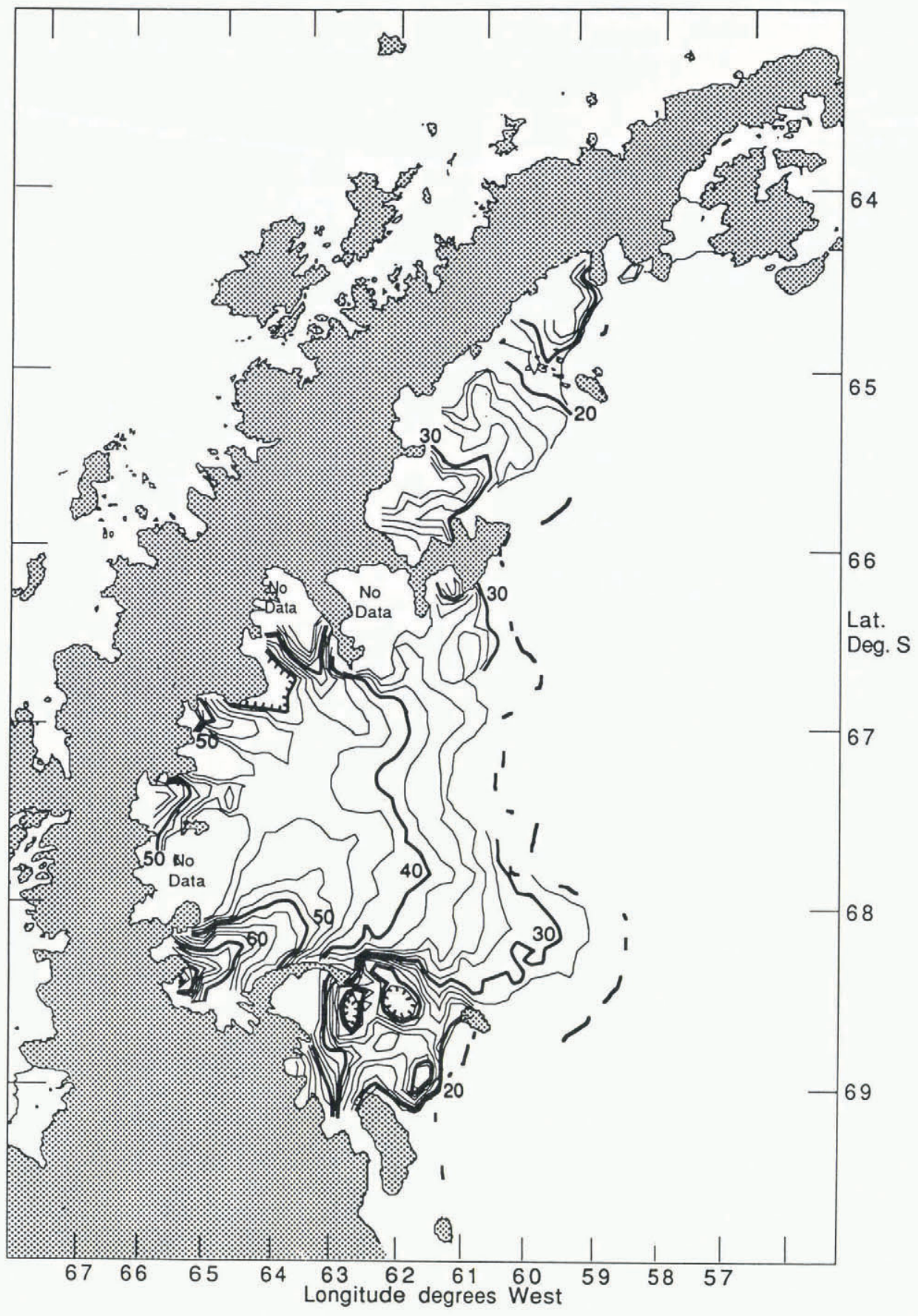

Fig. 5. Elevation map of the Larsen Ice Shelf derived from Seasat elevation data, contoured at a $2 \mathrm{~m}$ interval with $10 \mathrm{~m}$ contours shown in bold. Contours have been deleted in areas believed to display contamination from off-nadir reflections or artefacts of the automatic contouring. Also shown is the coastline derived from overpasses by the Seasat altimeter.

Nunataks where there is a trough only $18 \mathrm{~m}$ a.s.l. This area is also very flat and almost featureless with undulations no greater than $1 \mathrm{~m}$ in amplitude and wavelengths on the order of $100 \mathrm{~m}$. Although there may be many rif ts narrower than the $500 \mathrm{~m}$ detection limit of the techniques applied here, there are otherwise none observed.

\section{Central section}

Elevation contours for the central section of the ice shelf show its form to be dominated by the inflow of ice from Mobiloil and Cabinet Inlets, and to a lesser degree, by those from Mill and Whirlwind Inlets. Ice from Mobiloil Inlet extends in a broad elevated tongue, initially towards the north-east and then south-east as it flows along the northern edge of Kenyon Peninsula. This deflection occurs where it meets ice from Whirlwind, Cabinet, and Mill Inlets, and may also be controlled by back-pressure from a grounding point near the ice front (see below). The nose of ice which protrudes just north of Gipps Ice Rise seems to be composed entirely of ice originating in Mobiloil Inlet.
The tongues of ice flowing from the glaciers in Cabinet and Mill Inlets combine with that from Whirlwind Inlet and flow due east towards the seaward edge of the ice shelf. Most of this central part of the ice shelf lies between 30 and $45 \mathrm{~m}$ a.s.l. The total range is, however, from more than $80 \mathrm{~m}$ in Mobiloil Inlet to less than $30 \mathrm{~m}$ a.s.1. along most of the seaward edge. Between the two tongues of ice which emerge from the four major inlets (for instance, near Francis Island) are low-lying depressions about $10 \mathrm{~m}$ below the general surface of the ice shelf.

Some of the characteristics of the Seasat elevation data which are not evident after being partially averaged out in the process of binning and contouring can be seen in the altimeter profiles in Figure 6. Plot A illustrates the concave profile which is expected down an approximate flow line from a tributary glacier and also the smooth surface with very low gradients on the outer part of the ice shelf. The slightly asymmetric cross-flow profile of the Mobiloil Inlet outflow, the lower-lying and irregular surface near the rifts, and the low coastal cliff can be seen in plot B. 
Track A. Along Glacier

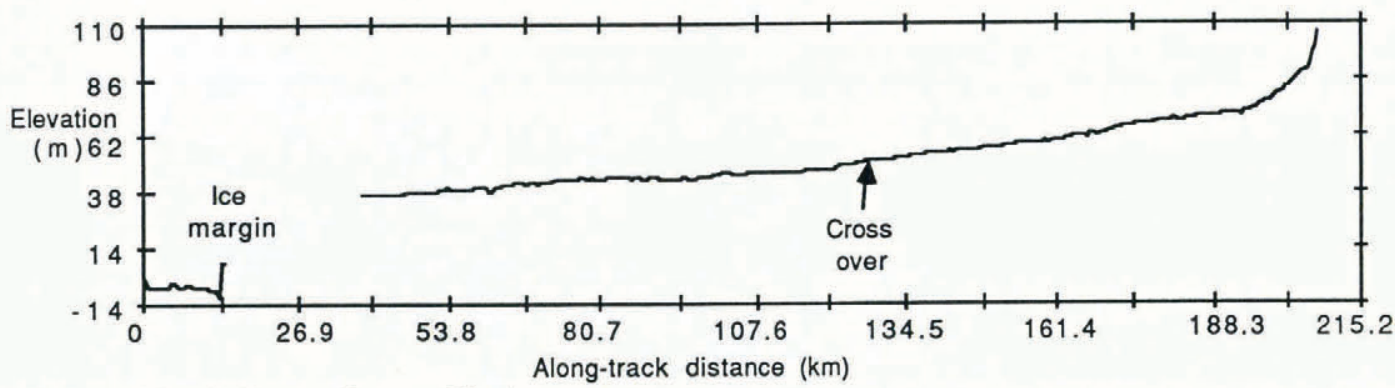

Track B. Cross Glacier

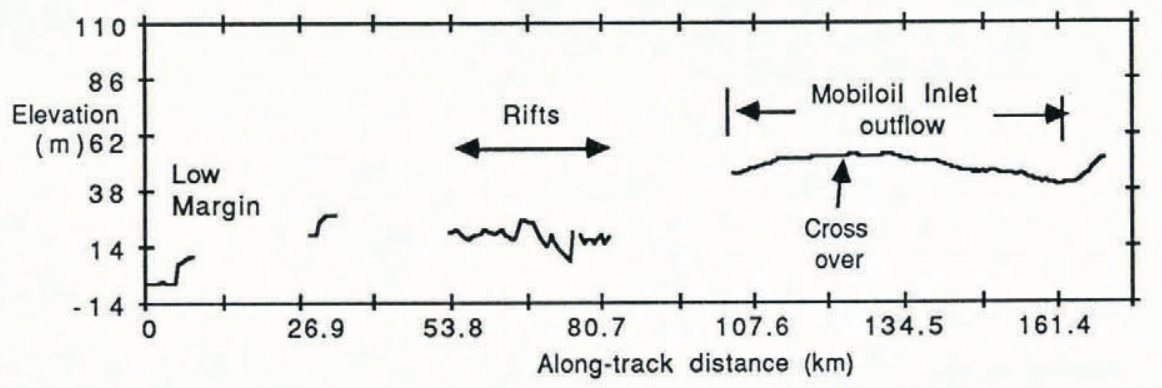

Fig. 6. Two profiles of surface elevation derived from Seasat altimetry, illustrating details of the ice-shelf surface which are averaged out in the process of contouring. Track $A$ illustrates the concave longitudinal profile of the tributary glacier and the smooth ice-shelf surface with very low gradients. Track $B$ shows the convex transverse profile of the Mobiloil Inlet outflow, the lower-lying series of rifts south of Kenyon Peninsula and the low, sloping edge to the ice shelf. The locations of tracks $A$ and $B$ are shown on Figure 1.

The distribution of roughness is found to be comparatively regular over much of this part of the ice shelf and areas with wave forms which display signs of crevassing tend to be small in size, no more than $10 \mathrm{~km}$ wide. Roughness estimates exceed $3.0 \mathrm{~m}$ for most of the inland margin, near to grounding points, down-stream of grounding points such as Francis and Tonkin Islands and along the northern margin of the outflow from Mobiloil Inlet. These are all circumstances in which stress differences may be expected to result in crevassing. Relatively smooth terrain (roughnesses of less than $1.0 \mathrm{~m}$ ) occurs in the centres of outflow tongues and down-stream from Cabinet, Whirlwind, and Mobiloil Inlets. This pattern is consistent with aerial photographs of the ice shelf (Ronne Antarctic Research Expedition, 1946-47) showing major disturbance and crevassing only at the boundaries of glacier outflows and irregular terrain near to grounding zones. The smoother, uncrevassed surfaces tend to occur away from obstructions to flow and where velocity gradients are low.

A large number of rifts occur on the lower parts of the Mobiloil Inlet outflow normal to the flow direction (Fig. 7). They are bounded to the south by the low-lying area described below. The dense track coverage enables them to be traced sometimes for tens of kilometres. Major rifts, where the altimeter has ranged to the rift floor result in the average elevation of the $0.1^{\circ}$ by $0.1^{\circ}$ bin to be lower than adjacent bins; this causes local inflections in the elevation contours. Lesser rifts are lost in the process of data averaging and binning.

\section{Southern section}

The most southerly section of the Larsen Ice Shelf is bounded to the north by Kenyon Peninsula and the outflow from Mobiloil Inlet, to the south by Hearst Island, and to its seaward side by Gipps Ice Rise. It has a very severe terrain. A clear discharge from Wakefield Highlands can be seen but a large depression with two areas less than $18 \mathrm{~m}$ a.s.l. result in high gradients and irregular contours.

The terrain is characterized by major north-south rif ts which emanate from a large partially enclosed depression. The rifts appear to have equal elevations on both sides and a rough horizontal floor, $3-6 \mathrm{~km}$ across, with back-scatter characteristics comparable with the top of the ice shelf. The depression itself is many tens of kilometres across and has surrounding cliffs which vary in height. Its floor is irregular over large distances and has a higher back-scatter than the surface of the ice shelf. The absence of multi-peaked wave forms indicates that there are no large melt ponds or expanses of bare ice.

\section{Ice-shelf margins}

The 41 intersections by Seasat altimeter ground tracks of the Larsen Ice Shelf's seaward margin analysed here enable approximately $30 \%$ of its length to be fixed (Fig. 7). There is, by and large, good agreement with the coastline of Figure 1 (from British Antarctic Survey, 1979; Directorate of Overseas Surveys, 1981), although a few general differences and specific changes should be noted. To the north of Jason Peninsula and south of Kenyon Peninsula, the locations show virtually no change, suggesting either relatively stagnant ice conditions or a balance between forward velocity and iceberg calving. The absence of marked inflow of land ice to these areas suggests that the former is more probable. In the central section between these two peninsulas, the margins derived from the two sources vary. From lat. $68^{\circ}$ to $68^{\circ} 40^{\prime} \mathrm{S}$. and $67^{\circ}$ to $67^{\circ} 50^{\prime} \mathrm{S}$., there has been a fairly uniform forward movement of $12-18 \mathrm{~km}$ but the overall form of the coastline has been retained. This may be taken to indicate that little calving has occurred. At lat. $67^{\circ} 54^{\prime} \mathrm{S}$., the form and position of a narrow embayment has remained unaltered and, given the appparent movement of the ice on either side, this stable feature may represent an area of local grounding.

At the eastern limit of Jason Peninsula, the altimeterdetected margin shows the ice cliff within just a few kilometres of the land margin. This differs by up to $15 \mathrm{~km}$ from the ice-shelf margin shown on the British Antarctic Survey (1979) and Directorate of Overseas Surveys (1981) coastlines. Therefore, either there has been a significant calving of the ice shelf from an area up to $50 \mathrm{~km}$ by $15 \mathrm{~km}$, or the original mapping of the ice-shelf margin (which was carried out using an areal survey) may have erroneously included some sea ice adjacent to the ice front. The absence of significant glaciers as a source of ice shelf at the outer end of Jason Peninsula would imply that the latter solution is more likely. This may be an instance of the difficulty of resolving from imagery such as Landsat 


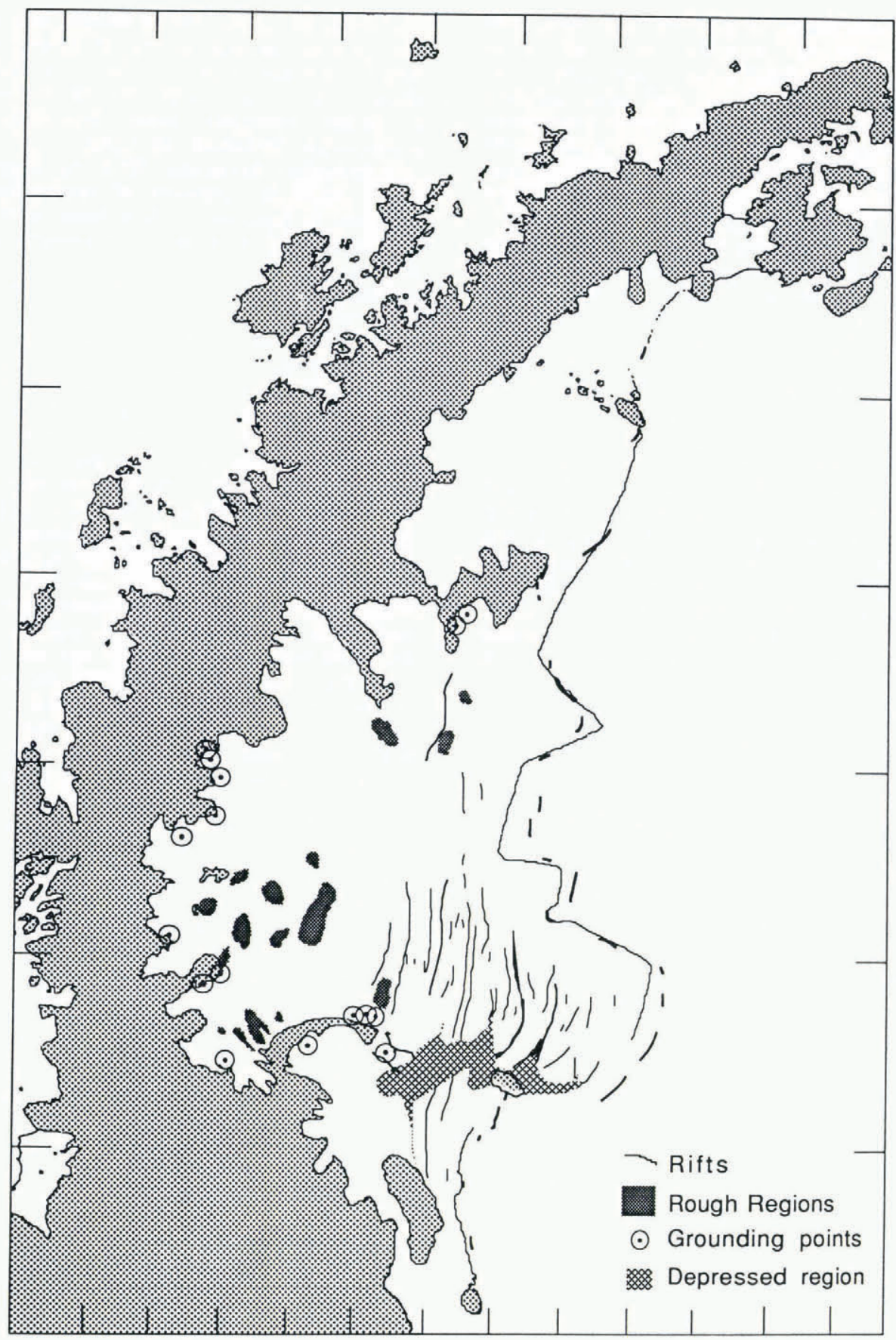

Fig. 7. A map of areas of surface roughness (crevassing or heavy sastrugi), of major rifts and low-lying areas, and of grounding points, all determined from altimetry. Also shown is the altimeter-derived coastline (heavy dashes) for the period of July and August 1978 and an earlier compilation of the coastline locations from British Antarctic Survey (1979) and Directorate of Overseas Surveys (1981) (thin continuous line).

and AVHRR ice-shelf margins when they are flanked by sea ice. The combined use of altimetry and imagery appears to provide a more reliable technique.

The detection of the ice-shelf grounding line was much more difficult that the detection of the seward margin due to the irregular nature of the terrain in the vicinity of the grounding line. However, of the 16 cases where determination of a location was possible, the agreement with the coastline shown in Figure 7 was in most cases within $1-3 \mathrm{~km}$. The most significant of fset between the two occurs in the vicinity of Kenyon Peninsula; along the northern edge, a marked break in gradient runs almost parallel to the land. This may represent a wedge of stagnant ice separating the outflow of Mobiloil Inlet from the adjacent peninsula. This is supported by the fact that further down-glacier the boundary between the tongue of ice from Mobiloil Inlet and the area of low-lying and disturbed ice to the south also occurs well away from the land and its projected flow line.

\section{Derived ice thicknesses}

Estimates of the thickness of the ice shelf may be derived by assuming conditions of hydrostatic equilibrium. This may be derived from surface elevation using (Renner, 1969):

$$
H=\left[E g+X\left(\rho_{\mathrm{X}}-\rho_{\mathrm{i}}\right) / \rho_{\mathrm{W}}\right] /\left(1-\rho_{\mathrm{i}} / \rho_{\mathrm{W}}\right)
$$

where $H$ is the total ice-shelf thickness, $E g$ is the surface elevation relative to the geoid, $X$ is the thickness of an upper layer of variable density, $\rho_{W}$ and $\rho_{i}$ are the densities of water and ice respectively, and $\rho_{X}$ is the mean density for the upper layer. Using values for the Larsen Ice Shelf from Renner (1969), Equation (4) reduces to

$$
H=8.3 E g-83 .
$$

Figure 5 may therefore be seen as a map of total ice thickness by converting the elevation contours of 20,30 , 
40,50 , and $60 \mathrm{~m}$ to thicknesses of $83,166,249,332$, and $415 \mathrm{~m}$, respectively, with an accuracy of about $10 \mathrm{~m}$ providing the ice is in hydrostatic equilibrium. The ice-thickness estimates can be compared with those obtained from the radio-echo surveys of Renner (169) and Ewen Smith (1972). These surveys were limited in extent with most flight tracks being confined to the inland part of the ice shelf between Joerg and Churchill Peninsulas, while only four profiles extended to the ice shelf's seaward margin.

The general form of the ice-thickness contour map given in Ewen Smith (1972) is consistent with that derived from the Seasat data, although the latter shows considerably more detail. Both reveal elevated tongues of ice emanating from the four major tributary glaciers in the ice shelf's central section, and a gradual slope with near-parallel contours within $50 \mathrm{~km}$ of the seaward margin. In detail, however, the two maps differ considerably. All of the glacier tributaries defined by Seasat altimetry may be traced as separate entities $20-50 \mathrm{~km}$ further into the ice shelf, especially that from Mobiloil Inlet. Such local differences may be due to errors in aircraft positioning (a locational accuracy of up to $15 \mathrm{~km}$ was quoted) and averaging and extrapolation errors due to contouring from sparse and non-uniform data coverage. More importantly, the ice thicknesses derived from the two sources appear to differ over several parts of the ice shelf. This offset is compared in Figure 8 along two transects whose locations are shown
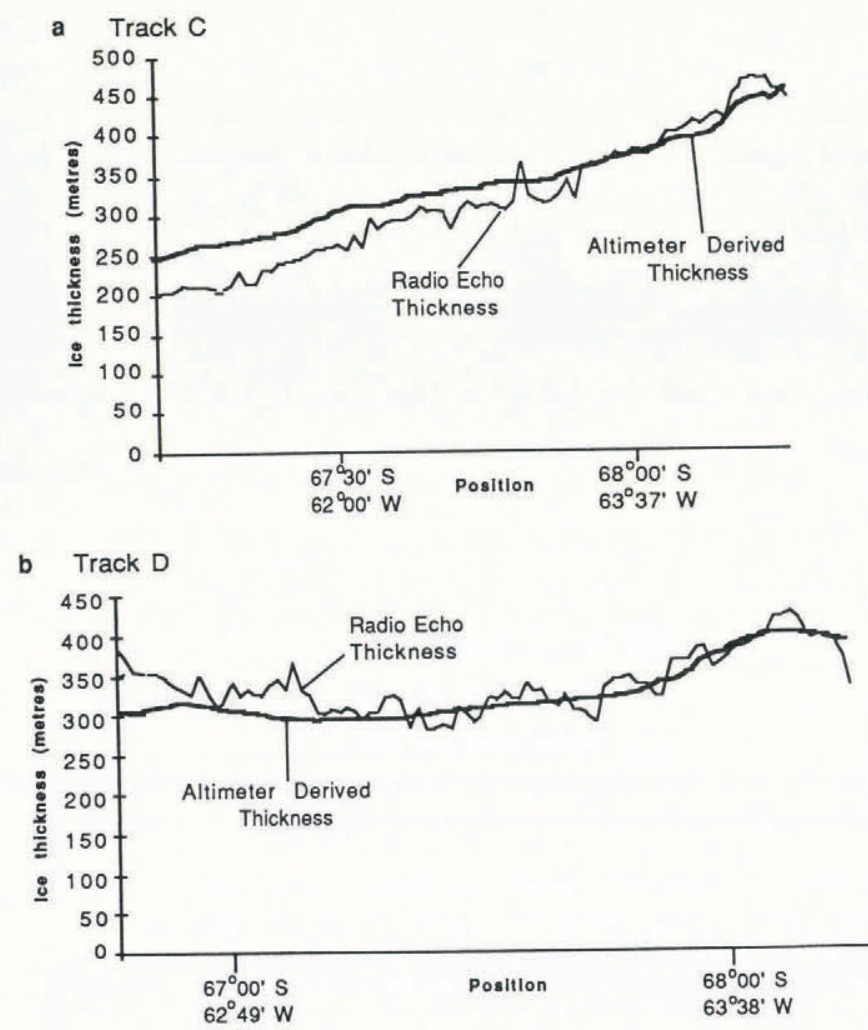

Fig. 8. Two comparisons of ice-thickness data, each showing results measured from airborne radio echo-sounding (Ewen Smith, 1972) and derived from Seasat surface-elevation data in Figure 4 using Equation (5). The locations of the two profiles are shown in Figure 1.

in Figure 1. The smoother profile of satellite-derived ice thicknesses is due to the binning of the altimeter data needed to construct the contour map and the averaging effect of the altimeter's larger footprint. In Figure 8a, there is shown to be good agreement in the innermost $50 \mathrm{~km}$ of the two profiles but seawards the Seasat derived thickness is greater by up to $50 \mathrm{~m}$. The transect in Figure $8 \mathrm{~b}$, which runs almost north-south across the inner part of the ice shelf, shows broad agreement but with differences between the two profiles of up to $50 \mathrm{~m}$ near Churchill Peninsula. Agreement is thus less good in the areas of rough terrain depicted in Figure 6.

Several reasons may account for the observed differences. First, the inner parts of the ice shelf are characterized by steeper gradients and rougher terrain; the aircraft's navigational errors of $15 \mathrm{~km}$ could well introduce errors in measured ice thickness of tens of metres (e.g. a slope of $0.01^{\circ}$, a typical slope in the area of track D, and a $15 \mathrm{~km}$ positional error give rise to an error in comparative thicknesses of $22 \mathrm{~m}$ ).

Secondly, deviations from the assumed density profile could result in variations of several metres in the second constant in Equation (5) and hence errors of tens of metres in the derived thickness. A systematic change in the value of $\left(1-\rho_{\mathrm{i}} / \rho_{\mathrm{w}}\right)$, resulting from a reduction in the accumulation rate across the ice shelf, could account for some of the anomaly.

Thirdly, Equation (5) assumed hydrostatic equilibrium. The influence of known grounding points and other, as yet, undetected ones may result in erroneous estimates of the Seasat-derived ice-shelf thickness values.

Fourthly, we note that the geoid is poorly mapped in Antarctica and a $40 \mathrm{~m}$ ice-thickness difference might be accounted for by a $5 \mathrm{~m}$ error in the geoid. However, the geoid-elevation difference from the GEM10B model is $5.5 \mathrm{~m}$ across the ice shelf and an additional $5 \mathrm{~m}$ difference over this relatively short distance (as is required to explain the trend in Figure 8a) seems unlikely. Finally, it has been noted that, although the elevations mapped in Figure 5 are relative to the GEM10B geoid, the sea-level, at the time of the reference orbit, just off the ice shelf is $4.8 \mathrm{~m}$ lower than the geoid. An analysis of the sea-level measured on all the tracks just prior to the ice edge reveals that the mean sea-level is $3.80 \mathrm{~m}$ lower than the GEM10B geoid with a variation from -5.66 to $-2.51 \mathrm{~m}$ about this mean presumed to be due to the local tides. A comparison with the GEM-T1 geoid reveals a $2.5 \mathrm{~m}$ difference between the two models. Even so, GEM-T1 still predicts a mean sea-level $1.3 \mathrm{~m}$ higher than is observed. Here we have mapped the ice shelf with respect to GEMIOB and this geoid error is only important in the comparison of ice-thickness measurements. To calculate the height of the ice shelf above sea-level (rather than the geoid), the $4.8 \mathrm{~m}$, arising from the measured difference in the reference orbit, is added to the contoured elevations.

Although it is possible that the discrepancies between the aircraft and Seasat data may be within the extremes of the possible errors, it is apparent that the combined use of satellite altimetry and airborne radio echo-sounding may prove a useful means of detecting instances where model assumptions are not valid, for instance, in locating areas of grounding or lateral stress which invalidate the assumption of hydrostatic equilibrium.

\section{Surface back-scatter}

The surface back-scatter coefficient (Fig. 9) shows a fairly uniform distribution with variations of less than 3-4 dB over most of the ice shelf. A gradation may however be seen between the seaward and inner parts of the central section. While the outer part of the ice shelf generally has a back-scatter coefficient of 9-10.5 dB, there is a belt extending from Mobiloil Inlet to Churchill Peninsula for which a back-scatter coefficient of 12 or $13 \mathrm{~dB}$ is more typical. It is interesting to note that this pattern is reversed north of Jason Peninsula with higher values of back-scatter coefficient occurring at the coast. These areas of higher reflectivity do not seem to bear any obvious relation to the elevation of the surface or its apparent exposure age. On the basis of modelling the response of back-scatter to changing surface characteristics, an increase in back-scatter coefficient of $2.5 \mathrm{~dB}$ can be expected from an increase in snow density from 0.3 to $0.4 \mathrm{Mg} \mathrm{m}^{-3}$ or a change in the formzahl of the grains from 2 to 25 (Ridley and Partington, 1988). Thus, the variations in back-scatter are likely related to the character and structure of the surface layers which may result from the dominant local weather conditions or patterns of snow accumulation, in particular the effects of wind.

\section{CONCLUSIONS}

Contour maps of surface elevation to an absolute accuracy of $1.0 \mathrm{~m}$ and radar back-scatter to an accuracy of $2.0 \mathrm{~dB}$ have been produced for the Larsen Ice Shelf using 


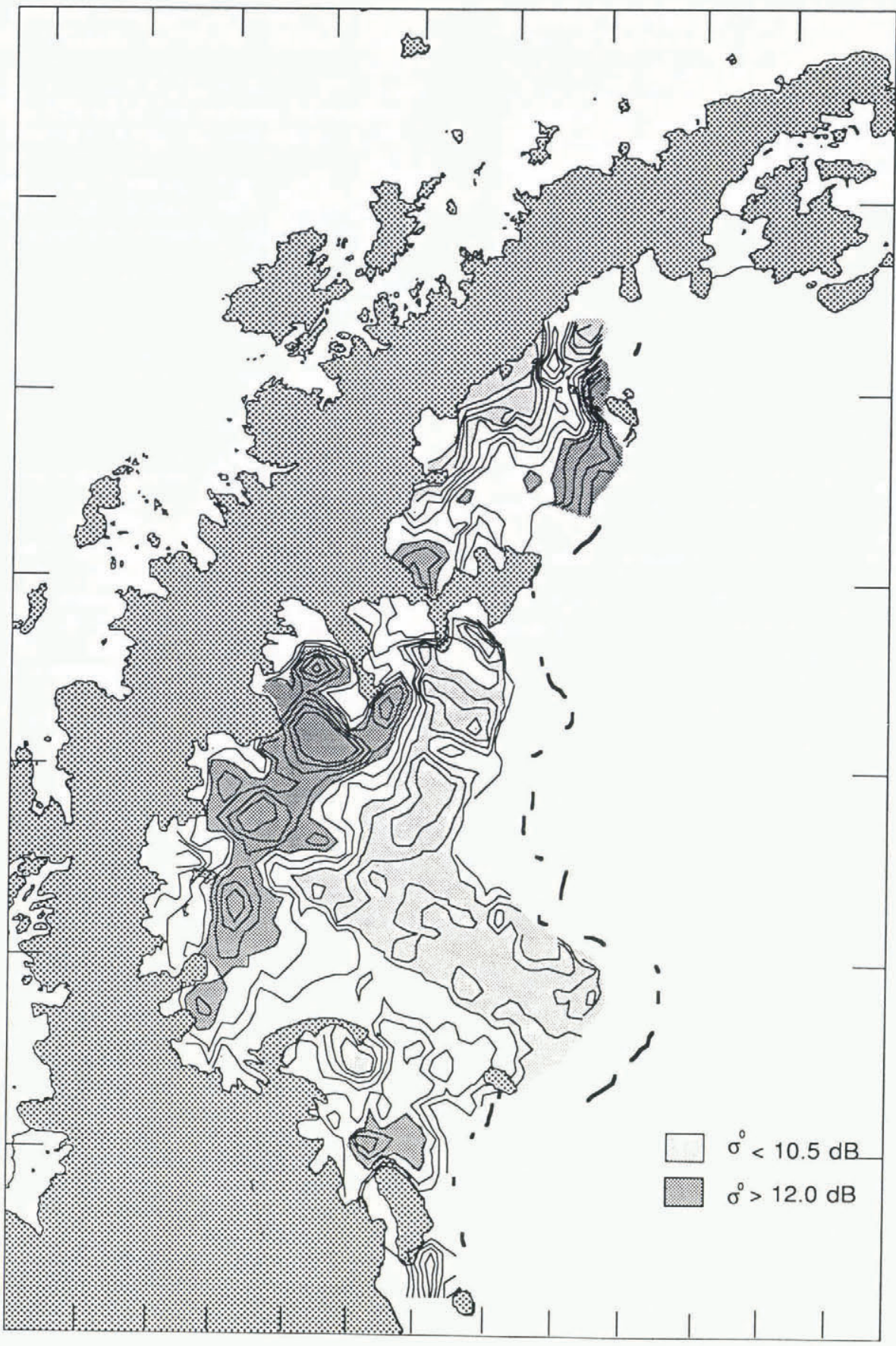

Fig. 9. A map of vertical incidence back-scatter contoured at $0.5 \mathrm{~dB}$ and with areas shaded below and above 10.5 and $12.0 \mathrm{~dB}$, respectively. Contours have been deleted in areas believed to display contamination from off-nadir reflections or artefacts of the automatic contouring. Also shown is the coastline derived from overpasses by the Seasat altimeter.

Seasat altimetry data. A detailed analysis of the altimetric wave-form shapes has also enabled a map of surface features, including rifts, zones of roughness, possible grounding points, and about $30 \%$ of the ice margin, to be contructed. The surface-elevation map clearly shows flow features, arising from the inlet glaciers, and the gradual distribution of this mass throughout the ice shelf. From these elevations, ice thickness and, where this is not in agreement with echo-sounding data, possible bottomgrounding sites may be deduced. Comparison of the ice-thickness estimates with those measured by earlier radio echo-sounding shows reasonable agreement except in the seaward parts of the ice shelf.

One possible indicator of climatic change is the thinning rate of ice shelves. Work on the Ross Ice Shelf (Thomas and others, 1988) has revealed that in some areas the ice is thinning at a rate of greater than $0.2 \mathrm{~m}$ per year. This corresponds to an elevation change, assuming hydrostatic equilibrium, of about $0.024 \mathrm{~m}$ per year. Over 10 years (the time interval between measurements by the Seasat and Geosat satellites), with a constant thinning, the elevation change that we would be required to be able to measure to detect this would be $0.24 \mathrm{~m}$. Thus, the survey height accuracy of $\pm 1 \mathrm{~m}$ obtained from the radar-altimeter data, although very much better than previously available, is only adequate to detect very major changes in the ice-shelf thickness. Nevertheless, this mapping of the Larsen Ice Shelf using satellite-altimetry represents a very substantial improvement over previous surveys. Furthermore, the analysis provides a reference from which future work, based on Geosat and ERS-1 altimetric data, will be able to reveal any long-term variations in the ice shelf's characteristics and will aid in detailed studies of the dynamics of ice shelves in general.

\section{ACKNOWLEDGEMENTS}

The authors are grateful to the staff of the Algorithm Development Facility at the Earth Observation Data Centre in Farnborough for abstracting parts of the Seasat data set, to J. Marsh and his staff for access to the high-accuracy 
Seasat orbit data, to $P$. Searle of the British Antarctic Survey for access to map and photographic collections, to C. Doake, A. Jenkins, P. Searle, D. Mantripp, and an anonymous referee for review comments, to members of the MSSL Remote Sensing Group for discussions on altimetry, and to the U.K. Natural Environment Research Council, the British Antarctic Survey, and the U.K. Science and Engineering Research Council for funding.

\section{REFERENCES}

British Antarctic Survey. 1979. Northern Graham Land and South Shetland Islands. British Antarctic Territory geological map, scale 1:500,000. Cambridge, British Antarctic Survey. (BAS 500G Sheet 2, Ed. 1.)

Brooks, R.L., W.J. Campbell, R.O. Ramseier, H.R. Stanley, and H.J. Zwally. 1978. Ice sheet topography by satellite altimetry. Nature, 274(5671), 539-543.

Brooks, R.L., R.S. Williams, jr, J.G. Ferrigno, and W.B. Krabill. 1983. Amery Ice Shelf topography from satellite radar altimetry. In Oliver, R.L., P.R. James, and J.B. Jago, eds. Antarctic earth science. Canberra, Australian Academy of Sciences, 441-445.

Brown, G.S. 1977. The average impulse response of a rough surface and its applications. IEEE Trans. Antennas Propag., AP-26(3), 472-482. [Erratum in IEEE Trans. Antennas Propag., AP-28, 1980, 943-948.]

Directorate of Overseas Surveys. 1981. British Antarctic Territory (north of $82^{\circ} \mathrm{S}$ ) with South Georgia and the South Sandwich Islands, scale 1:3M. London, Directorate of Overseas Surveys for the British Antarctic Survey. (BAS (Misc.) 2, Ed. 1.)

Ewen Smith, B.M. 1972. Airborne radio echo sounding of glaciers in the Antarctic Peninsula. Br. Antarct. Surv. Sci. Rep. 72.

Fleet, M. 1965. The occurrence of rifts in the Larsen Ice Shelf near Cape Disappointment. Br. Antarct. Surv. Bull. 6, 63-66.

Hughes, T.J. 1973. Is the West Antarctic ice sheet disintegrating? J. Geophys. Res., 78(33), 7884-7910.

Jacobs, S. and D. Barnett. 1987. On the draughts of some large Antarctic icebergs. Iceberg Res., 14, 3-13.

Kennett, P. 1965. Use of aneroid barometers for height determinations on the Larsen Ice Shelf. Br. Antarct. Surv. Bull. 7, 77-80.

Kennett, P. 1966. Reconnaissance gravity and magnetic surveys of part of the Larsen Ice Shelf and adjacent mainland. Br. Antarct. Surv. Bull. 8, 49-62.

MacArthur, J.L. 1978. Seasat-A radar altimeter design description. Baltimore, MD, Johns Hopkins University. Applied Physics Laboratory. (SDO-5232.)
Marsh, J.G. and T.V. Martin. 1982. The SEASAT altimeter mean surface model. J. Geophys. Res., 87(C5), 32693280 .

Marsh, J.G., and 6 others. In press. Dynamic sea surface topography, gravity, and improved orbit accuracies from a direct evaluation of Seasat altimetry data. J. Geophys. Res.

Martin, T.V., H.J. Zwally, A.C. Brenner, and R.A. Bindschadler. 1983. Analysis and retracking of continental ice sheet radar altimeter waveforms. J. Geophys. Res., 88(C3), 1608-1616.

Mason, D. 1950. The Larsen shelf ice. J. Glaciol., 1(8), 409-413.

Partington, K.C., W. Cudlip, N.F. McIntyre, and S. King-Hele. 1987. Mapping of Amery Ice Shelf, Antarctica, surface features by satellite altimetry. Ann. Glaciol., 9, 183-188.

Reece, A. 1950. The ice of Crown Prince Gustav Channel, Graham Land, Antarctica. J. Glaciol., 1(8), 404-409.

Renner, R.G.B. 1969. Surface elevations on the Larsen Ice Shelf. Br. Antarct. Surv. Bull. 19, 1-8.

Ridley, J.K. and K.C. Partington. 1988. A model of satellite radar altimeter return from ice sheets. Int. $J$. Remote Sensing, 9(4), 601-624.

Robin, G. de Q. 1979. Formation, flow, and disintegration of ice shelves. J. Glaciol., 24(90), 259-271.

Ronne Antarctic Research Expedition, 1946-47. Unpublished. Aerial photographs archived at British Antarctic Survey, Cambridge.

Swithinbank, C.W.M., P. McClain, and P. Little. 1977. Drift tracks of Antarctic icebergs. Polar Rec., 18(116), 495-501.

Thomas, R.H., T.V. Martin, and H.J. Zwally. 1983. Mapping ice-sheet margins from radar altimetry data. Ann. Glaciol., 4, 283-288.

Thomas, R.H., S.N. Stephenson, R.A. Bindschadler, S. Shabtaie, and C.R. Bentley. 1988. Thinning and grounding-line retreat on Ross Ice Shelf, Antarctica. Ann. Glaciol., 11, 165-172.

Townsend, W.F. 1980. An initial assessment of the performance achieved by the Seasat-1 radar altimeter. IEEE J. Oceanic Eng., OE-5(2), 80-92.

Wingham, D.J., C.G. Rapley, and H.D. Griffiths. 1986. New techniques in satellite altimeter tracking systems. In Guyenne, T.D. and J.J. Hunt, eds. IGARSS Symposium, Zürich, 8-11 September 1986. Proceedings. Paris, European Space Agency, 1339-1344. (SP-254.)

Zwally, H.J., R.A. Bindschadler, A.C. Brenner, T.V. Martin, and R.H. Thomas. 1983. Surface elevation contours of Greenland and Antarctic ice sheets. J. Geophys. Res., 88(C3), 1589-1596.

Zwally, H.J., S.N. Stephenson, R.A. Bindschadler, and R.H. Thomas. 1987. Antarctic ice shelf boundaries and elevations from satellite radar altimetry. Ann. Glaciol., 9, 229-235. 